\title{
TRANSFERSOMAL GEL CONTAINING GREEN TEA (CAMELLIA SINENSIS L. KUNTZE) LEAVES EXTRACT: INCREASING IN VITRO PENETRATION
}

\author{
EFFIONORA ANWAR*, TAHMIDA DIAZPUTRI UTAMI, DELLY RAMADON
}

Faculty of Pharmacy, Laboratory of Pharmaceutics and Pharmaceutical Technology, Universitas Indonesia, Depok, West Java, Indonesia. Email: effi.nora@gmail.com

Received: 13 April 2017, Revised and Accepted: 15 May 2017

\section{ABSTRACT}

Objective: The aim of this study was to increase penetration of epigallocatechin gallate (EGCG) from green tea leaves extract (Camellia sinensis L. Kuntz) through the skin by formulating the extract into a transfersomal gel (GT).

Methods: Transfersomes were prepared by thin-layer hydration method, with different concentration of the extract that equivalent to 1\% (F1), 1.5\% (F2), and 2\% (F3) of EGCG. A transfersomes formula with good characteristics would be incorporated into a GT. A gel without transfersomes (GNT) was prepared as a control of comparison. Both gels were evaluated their physicochemical properties. An in vitro penetration test using Franz diffusion cell with the skin of female Sprague-Dawley rats was also performed.

Results: The results showed that $\mathrm{F} 1$ had the best physicochemical properties. F1 had a spherical shape, $\mathrm{D}_{\text {mean }}$ volume at $107.82 \pm 0.44$ nm, polydispersity index at $0.07 \pm 0.01$, zeta potential at $-40.3 \pm 0.10 \mathrm{mV}$, and entrapment efficiency at $63.16 \pm 0.65 \%$. Cumulative amount of EGCG penetrated from GT and non-GT (GNT) was $1302.63 \pm 20.67 \mu \mathrm{g} / \mathrm{cm}^{2}$ and $414.86 \pm 4.40 \mu \mathrm{g} / \mathrm{cm}^{2}$, respectively $(\mathrm{p}<0.05)$. Flux penetration of GT and GNT was $57.594 \pm 0.91 \mu \mathrm{g} / \mathrm{cm}^{2} \mathrm{hrs}$ and $36.144 \pm 1.22 \mu \mathrm{g} / \mathrm{cm}^{2}$. hrs, respectively.

Conclusion: It can be concluded that GT could increase the in vitro penetration of EGCG from green tea leaves extract compared to non-transfersomal one.

Keywords: Epigallocatechin gallate, Green tea leaves extract, In vitro penetration test, Transfersomes, Transfersomal gel.

(C) 2017 The Authors. Published by Innovare Academic Sciences Pvt Ltd. This is an open access article under the CC BY license (http://creativecommons. org/licenses/by/4. 0/) DOI: http://dx.doi.org/10.22159/ajpcr.2017.v10i8.19124

\section{INTRODUCTION}

At present, the development of pharmaceutical technology is increasing rapidly with the development of science and performance in the fulfillment of health. One of its developments is transdermal nanodosage form that can deliver a drug through the skin that serves as a medium of penetration into the systemic circulation. The benefits transdermal dosage form are easy to use, passing the first metabolism in the liver, can be a controlled release dosage form, and good for drugs that have an oral bioavailability problem [1,2]. Transdermal drug delivery is also tricky because the skin, as a natural barrier, has a very low permeation rate. A range of molecules that can achieve therapeutic amounts at their target site following application to the skin is severely limited, due to the effective barrier properties of intact skin, which is primarily associated with the outermost layers of the epidermis, namely, the stratum corneum [3]. To overcome the penetration problems, it can be done with nanovesicle such as lipid nanovesicular as transfersomes.

One development of nanovesicle systems that can be formulated in transdermal dosage forms is transfersomes. Transfersomes are a hydrophilic ultra-deformable lipid vesicle loaded with active pharmaceutical ingredients and applied to the skin in an aqueous formulation. It consists of phospholipids and an edge activator which is generally a single chain surfactant with a high radius of curvature. Phospholipids like phosphatidylcholine self-assembles into lipid bilayer, in an aqueous environment and closes to form a vesicle. In addition, edge activators are responsible for weakening the vesicles' lipid bilayers increasing their flexibility and deformability allowing them to be squeezed through pores of the stratum corneum. Sodium cholate, sodium deoxycholate, Span 60, Span 65, Span 80, Tween 20, Tween 60, Tween 80 , or dipotassium glycyrrhizinate are commonly used as edge activators $[4,5]$. Surfactants increase the deformability of the vesicle, as well to increase the penetration of the drug into the skin tissue and through the skin layer to the systemic [6]. Transfersomes are supposed to cross the skin under the influence of a trans-epidermal water activity gradient which is considered the driving force for vesicle penetration through the skin [7]. Surfactant was used to improve the vesicle deformability so that it can increase the drugs penetration through the skin via skin layers until they reach the systemic circulation system [8]. Transfersomes could act as efficient carriers for a deeper layer of the skin. Transfersomes are a deformable, elastic, and flexible vesicle that can be used to deliver drugs and genetic material. Furthermore, transfersomes have the ability to entrap hydrophilic and lipophilic molecules, and target drugs in organs or tissues [9]. Transfersomes can entrap active substances in the form of chemicals and natural materials.

Nowadays, people often choose natural products as the main treatment or just as a complementary medicine for some diseases. Some other people believe that natural products can also be used as an ingredient in cosmetics. One of the most important natural products that has been used since a long time ago and proven safe and has many benefits as a source of medicine one of them is green tea (Camellia sinensis L. Kuntze) [10]. The largest compound content in green tea that has many benefits is a catechin derived compound, namely, epigallocatechin gallate (EGCG). EGCG has a high antioxidant activity that can protect the body from the risk of some diseases such as cardiovascular disease, diabetes mellitus, cancer, neurodegenerative disorders, and can provide anti-inflammatory effects $[11,12]$.

However, the biologically active constituents of plants, such as flavonoids and phenolic compounds, are mostly polar or watersoluble molecules. EGCG has a low absorption in the small intestine 
that is $<5 \%$ of EGCG absorbed into the blood circulation [13]. EGCG that does not enter the blood circulation will enter through the small intestine and into the colon and degraded by the micro flora of the large intestine [14]. Furthermore, it is poorly absorbed when administered transdermally. EGCG is a hydrophilic molecule with a high polarity value $(\log \mathrm{p}=0.48)$ thus inhibiting its penetration into the skin [15]. In overcoming this, green tea leaves extract can be formulated into a vesicle system or a carrier based lipid, i.e., transfersomes. Transfersomes are efficient to deliver natural products, especially for a high molecular weight drugs such as EGCG. This transdermal transfersomes formulation of green tea leaves can be made into a semisolid dosage formulation. Semisolid dosage form which is often used as transfersomes carriers is gel

Gel can hydrate the skin because it has high enough water content so that the penetration of drugs is better [16]. Based on Avadhani et al., EGCG had been formulated into a transfersome, but the material used was pure chemical substances and not an extract [17]. Furthermore, they did not formulated the transfersome into a gel dosage form.

In this study, transfersomes of green tea leaves extract were used as active ingredient in the gel formulation. The aim of this study is to increase the in vitro penetration of EGCG from green tea leaves extract by formulating them into transfersomal gel (GT).

\section{MATERIALS AND METHODS}

\section{Materials}

Green tea leaves extract (C. sinensis L. Kuntz) was purchased from Andy Biotech (Xi' an) Co., Ltd. Phospholipid (Lipoid P30) kindly provided from Lipoid GMBH (Germany) with purity of more than $97 \%$ phospholipids, and the content of phosphatidylcholine is approximately $30 \%(\mathrm{w} / \mathrm{w})$. The other chemical reagents were analytical grade.

\section{Preparation of transfersomes}

Three transfersomes formulae were prepared by thin film hydration method. They contained green tea leaves extract, soya lecithin (Lipoid P30), and surfactants (Span 80). The amount of extract added was various (Table 1). Lipoid P30 and Span 80 were dissolved in dichloromethane, and the solvent was evaporated in a round bottom flask using rotary evaporator at a temperature of $37 \pm 1^{\circ} \mathrm{C}$ at a speed of $150 \mathrm{rpm}$. The thin-layer formed was then flowed by nitrogen and incubated for $24 \mathrm{hrs}$ in the refrigerator. Then, it was hydrated using phosphate buffer solution $\mathrm{pH}$ 5.5. The hydration process was done at a temperature of $37 \pm 1^{\circ} \mathrm{C}$ at $150 \mathrm{rpm}$. The transfersomes suspension was produced, then the particle size was reduced by ultrasonication for 10 minutes in 25 amplitude [18,19].

Particle size distribution, polydispersity index, and zeta potential The particle size distribution of transfersomes was determined by dynamic light scattering method (DLS), using a particle size analyzer (Malvern Zetasizer). Transfersomes suspension was diluted with distilled water up to $10 \mathrm{ml}$, then the particle size and zeta potential were measured. The determination was conducted in 3 times [1].

\section{Morphology of the transfersomes}

In this research, the morphology of transfersomes was analyzed using transmission electron microscope (TEM) (JEOL JEM 1400). The sample was dropped onto a copper grid size $400 \mathrm{~nm}$; then the transfersomes were air-dried in room temperature. After drying, the grid was observed using TEM at 5000-50000 magnification with an acceleration voltage of $80 \mathrm{kV}[20]$.

\section{Determination of entrapment efficiency}

The amount of drug entrapped was estimated by ultracentrifugation method. The prepared transfersomes suspension $(1 \mathrm{ml})$ was placed in a centrifugation tube and centrifuged at $13000 \mathrm{rpm}$ for $1 \mathrm{hr}$. The supernatant was withdrawn and precipitated, then diluted with phosphate buffer solution ( $\mathrm{pH} 5.5$ ) to wash them from unentrapped green tea extract. The sedimentation was added by chloroform and ethanol. Then, the drug concentration was determined using thin layer chromatography (TLC) densitometer. The entrapment efficiency is expressed as the percent of EGCG entrapped [21].

$$
\text { Entrapment efficieny }=\frac{\text { Amount drug entrapped }}{\text { Total amount durg added }} \times 100 \%
$$

\section{Deformability index test}

Deformability index was measured by an extrusion method. Transfersomes suspension was passed through polycarbonate membrane which the pore size of the barrier membrane was $0.1 \mu \mathrm{m}$ in mini extruder. The amount of transfersomes which was passed through extruded during 5 minutes was recorded [22]. The experiment was performed in triplicate. The degree of deformability is calculated using the following equation.

$$
D=J x\left(\frac{r_{v}}{r_{p}}\right)^{2}
$$

Where $D$ is the deformability of vesicle membrane, $J$ is the amount of suspension passed through in 5 minutes, $r v$ is the size of vesicle (after passed), and $r p$ is the pore size of the barrier.

\section{Preparation and evaluation of gel}

The composition of GT containing green tea extract formulations is shown in Table 2.

An appropriate amount of carbopol was dispersed in demineralized water for $24 \mathrm{hrs}$, then the $\mathrm{pH}$ of carbopol gel was adjusted using triethanolamine while stirred until a homogenous gel was formed. After that, transfersomes of green tea extract were mixed into the gel base in the homogenizer and stirred at $1500 \mathrm{rpm}$ for 15 minutes. Similarly, gel containing green tea extract without transfersomes was prepared by the same method as a comparative standard [23].

\section{Physical evaluation and $\mathrm{pH}$}

Organoleptic test, such as homogeneity, color, odor, viscosity, and rheology properties, was conducted. The $\mathrm{pH}$ value of the gels was measured using digital $\mathrm{pH}$ meter (Eutech $\mathrm{pH} 510$, Singapore) at the room temperature.

Table 1: Transfersomes formulation

\begin{tabular}{llll}
\hline Materials & \multicolumn{3}{l}{ Concentration (\%) (w/v) } \\
\cline { 2 - 4 } & F1 & F2 & F3 \\
\hline $\begin{array}{l}\text { Green tea leaves extract } \\
\text { equivalent to EGCG }\end{array}$ & 1.0 & 1.5 & 2.0 \\
Lipoid P30 & 4.0 & 4.0 & 4.0 \\
Span 80 & 0.7 & 0.7 & 0.7 \\
$\begin{array}{l}\text { Phosphate buffer solution } \\
\text { pH 5.5 }\end{array}$ & Up to 100 & Up to 100 & Up to 100 \\
\hline
\end{tabular}

EGCG: Epigallocatechin gallate

Table 2: Composition of gels

\begin{tabular}{lll}
\hline \multirow{2}{*}{ Substances } & \multicolumn{2}{c}{ Concentration (\%) (w/w) } \\
\cline { 2 - 3 } & GT & GNT \\
\hline Carbomer & 1.0 & 1.0 \\
Triethanolamine & 0.6 & 0.6 \\
Propylene glycol & 12.5 & 12.5 \\
Transfersome of green & Equal to EGCG 0.5 & - \\
tea leaves extract & & \\
Green tea leaves extract & - & Equal to EGCG 0.5 \\
Aqua demineralisata & Ad 100 & Ad 100 \\
\hline
\end{tabular}

GT: Transfersomal gel, GNT: Non-transfersomal gel, EGCG: Epigallocatechin gallate 
Physical stability of the gel study

Physical stability of the gel was conducted in three differenttemperatures at $4 \pm 2^{\circ} \mathrm{C}, 25 \pm 2^{\circ} \mathrm{C}$, and $40 \pm 2^{\circ} \mathrm{C}$. Then, the gels were evaluated including the organoleptic, $\mathrm{pH}$, viscosity, and rheology properties during storage for 12 weeks with interval 2 weeks of each observation. Another study was cycling test with six cycles for 2 weeks [24].

\section{In vitro penetration test}

For this study, in vitro penetration test was conducted using Franz diffusion cell with a receiver compartment volume of $15 \mathrm{ml}$ and effective diffusion area of $2.01 \mathrm{~cm}^{2}$. Abdominal skin of female Sprague-Dawley rats was used as a membrane. All of methods related to animal euthanizing have been approved by Ethical Clearance Committee of Cipto Mangunkusumo Public Hospital, Faculty of Medicine, Universitas Indonesia No. 418/UN.2F1/ETIK/2016. The abdomen skin was mounted horizontally on the receptor compartment with the stratum corneum side facing upward toward the donor compartment of Franz diffusion cell, and the other side facing downward into the receptor. The receptor was filled with $15 \mathrm{ml}$ of phosphate buffer solution (pH 5.5) maintained at a temperature of $37 \pm 0.5^{\circ} \mathrm{C}$ and stirred by a magnetic bar at $250 \mathrm{rpm}$. The gel dosage form $( \pm 1 \mathrm{~g})$ was placed on the rat skin, then the top of the diffusion cell was covered [15]. At appropriate time intervals $(1,3,5,7,8,10,12,14,16,18,20,22$, and $24 \mathrm{hrs}), 5 \mathrm{ml}$ aliquots of the receptor medium were withdrawn and immediately replaced by an equal volume of fresh receptor solution to maintain sink condition. The sample was then analyzed using TLC densitometer at wavelength $254 \mathrm{~nm}$. Each measurement was done in triplicate tested.

\section{Statistical analysis}

The data were analyzed using GraphPad Prism 6.0 via unpaired t-tests with significance level were set at $\mathrm{p}<0.05$

\section{RESULTS AND DISCUSSION}

Transfersomes are known as a deformable vesicle, which was first introduced in the early 1990s. In this study, the transfersomes composition was soya phosphatidylcholine and Span 80. The function of phospholipid is to form the lipid bilayer arrangement in vesicles. While non-ionic surfactant such as Span 80 is selected because this type of surfactant has a hydrophilic ethoxy group and a lipophilic hydrocarbon group to form a lipid bilayer arrangement of transfersome vesicles [25]. The process of vesicle formation due to the merging of phospholipids with span 80 which will form a spherical arrangement. Span 80 will fill the gap between the phospholipids that will form the arrangement of lipid bilayer [26].

\section{Morphology of transfersomes}

The results showed that all transfersomes formulae had characteristics as a spherical shaped particle as shown in Fig. 1. They also showed the lamellar of vesicle. However, the shape was not perfectly spherical or called as an irregular shape. This phenomenon was occurred because there was Span 80 that does not fill the gap between the phospholipids, so the formation and arrangement of lipid bilayer of vesicle were not perfect [26].

Particle size distribution, polydispersity index, and zeta potential Particle size was measured by particle size analyzer with DLS method. The results of this study can be seen in Table 3. Table 3 showed the summary results of transfersome characterizations. This study showed that the higher the EGCG concentrations in transfersomes formula, the bigger its particle size. The particle size can be influenced by the drug concentration in the vesicle [27]. When a high concentration of extract was added, the phospholipid and the surfactant could not entrap the extract perfectly. It results in the instability of vesicle integrity so that there is a vesicle aggregation into a larger one because the ratio of drug to phospholipid and surfactant is more than their maximum capacity. Besides the particle size, polydispersity index (PDI) of the particle was also measured. PDI is a parameter that shows the heterogeneity of particles. The lower value of PDI, the more homogenous the particle size [28]. A good value of PDI should be lower than 0.5. Based on this

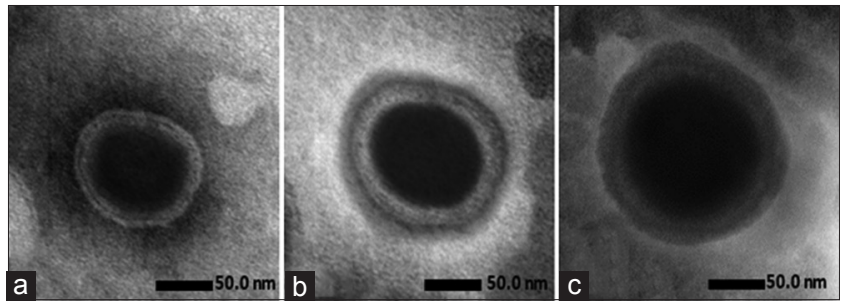

Fig. 1: Morphology of transfersomes green tea extract (transmission electron microscope), 150,000 magnification. (a) F1, (b) F2, and (c) F3

Table 3: Characteristics of green tea extract transfersomes

\begin{tabular}{llll}
\hline Parameter & F1 & F2 & F3 \\
\hline Vesicles morphology & Spherical & Spherical & Spherical \\
& shape & shape & shape \\
Mean volume (nm) & $107.82 \pm 0.44$ & $122.75 \pm 0.22$ & $182.57 \pm 2.62$ \\
Polydispersity index & $0.07 \pm 0.01$ & $0.159 \pm 0.00$ & $0.218 \pm 0.06$ \\
Zeta potential (mV) & $-40.30 \pm 0.10$ & $-37.7 \pm 0.40$ & $-35.5 \pm 0.63$ \\
$\begin{array}{l}\text { Entrapment } \\
\text { efficiency (\%) }\end{array}$ & $63.16 \pm 0.65$ & $45.79 \pm 0.19$ & $39.43 \pm 0.07$ \\
\hline
\end{tabular}

All values were represented as mean $\pm \operatorname{SD}(n=3)$

theory, all transfersomes formulae in this study showed a good PDI. There was an indirect correlation between drug concentrations added with the PDI. As mentioned above, the increase of drug concentration will increase the particle size. When there is a potential aggregation between the vesicles, the particle size cannot be maintained as the first it prepared. Consequently, the homogeneity of the particle decreases.

Another important factor for a transfersomes suspension is zeta potential. Zeta potential represents the repulsive potential between particles. A good suspension should have zeta potential higher than $+30 \mathrm{mV}$ or lower than $-30 \mathrm{mV}$ [28]. Table 3 showed that the zeta potential values of the three formulae were lower than $-30 \mathrm{mV}$. It indicated that all formulae will have a good stability. The zeta potential of suspension can be affected by $\mathrm{pH}$ of the solvent used, charge of drugs, and conductivity [27]. Negative charge of zeta potential may be associated to the charge of drugs entrapped (in this case extract containing EGCG), neutral charge of the phospholipids used and the medium of suspension [29].

\section{Entrapment efficiency}

The entrapment efficiency is expressed as the percentage entrapment of the active pharmaceutical ingredient added. Entrapment efficiency was determined by direct method [20]. Based on the data in Table 3, the best entrapment was F1. In this case, the increase of active substances concentration not followed by an increased concentration of phospholipid cannot improve the percentage of entrapment efficiency. Chaudhary et al. found that entrapment efficiency of transfersomes can be improved by increasing the lipid concentration of decreasing the concentration of surfactant [30]. It has been known that phospholipids have a maximum capacity to entrap drug inside the vesicle. When there are more drugs in the mixture, it results the saturation of drugs, and the phospholipid and surfactant cannot entrap them completely.

\section{Deformability index}

Deformability index test was conducted to determine the flexibility of transfersomes flexibility. These results will differentiate the transfersomes to other vesicles. Deformability test results obtained for F1, F2, and F3 were $1.03 \pm 0.00,1.21 \pm 0.00$, and $1.79 \pm 0.00$, respectively. Deformability indexvalue was influenced by phospholipid concentration and surfactant used. However, in this study, both substances were constantly used. Therefore, the deformability test results did not show many differences. The surfactant addition could cause micelles formation so that the deformability index will be lowered. The higher 
the deformability index value, the transfersomes vesicle will be more flexible, and the transfersomes could penetrate through the skin pores which have a smaller size than the vesicle [31].

\section{Gel evaluation}

Organoleptic properties were evaluated on the gel shown the non-GT (GNT) color was transparent orange, and $\mathrm{pH}$ value was 5.65 \pm 0.05 . Color of GT was whitish orange with $\mathrm{pH}$ value was $5.59 \pm 0.02$. The $\mathrm{pH}$ was suitable for active substance stability, especially for EGCG at pH 5.5 [32]. In addition, the $\mathrm{pH}$ of the gels was in the range of the $\mathrm{pH}$ of the skin (4.5-6.5).

\section{Viscosity and rheological properties of the gel}

For any gel formulations, the viscosity and rheological properties play an important role in determining the efficacy of the gel in delivering the active substance across the skin. Viscosity and rheological properties greatly affect spread ability, adhesiveness, drug release from semisolid formulations, and subsequent penetration through the skin [33-35]. The viscosity values of GNT were $3800 \mathrm{cps}$, and GT was $4300 \mathrm{cps}$. Rheology properties both of gels were pseudoplastic thixotropy. It means that it is easy to use on the skin.

\section{The gel physical stability}

The result showed that both gels' appearance and color were stable during storage condition at $4 \pm 2^{\circ} \mathrm{C}$ for 8 weeks at three temperatures, but at $25 \pm 2^{\circ} \mathrm{C}$ and $40 \pm 2^{\circ} \mathrm{C}$ temperature there were color changes on GNT become darker than the beginning. This changing occurred because the extract was not entrapped in the transfersomes. This phenomenon showed that transfersome has an ability to keep drug stability. It protects the drugs from the environment directly. The other properties such as viscosity, rheological properties, and $\mathrm{pH}$ value decrease slightly at three temperatures [35]. The decrease of viscosity, particularly in the GNT, can be caused by the decrease of the pH of the gels. In GNT, the extract was not entrapped in the transfersome, so that it interacted with the carbomer in the gel. As a gelling agent, the viscosity of carbomer is influenced by the $\mathrm{pH}$. The lower $\mathrm{pH}$ of the gel, the lower its viscosity.

\section{In vitro penetration test}

Fig. 2 showed the penetration profile of EGCG from both gels. Cumulative amount of EGCG penetrated from GT and GNT was $1302.63 \pm 20.67 \mu \mathrm{g} / \mathrm{cm}^{2}$ and $414.86 \pm 4.40 \mu \mathrm{g} / \mathrm{cm}^{2}$, respectively ( $\left.\mathrm{p}<0.05\right)$. Based on this data, it was indicated that gel transfersomes can increase the penetration and amount of active substance like EGCG.

Another important parameter of in vitro penetration study is flux. Flux is the amount of active substance penetrated crossing a membrane per unit area into the circulating system per unit time, and for in vitro permeation, this "system" is the receptor chamber, expressed in units of mass/area/ time [36]. Fig. 3 shown that flux of GT was $57.59 \pm 0.91 \mu \mathrm{g} / \mathrm{cm}^{2} . \mathrm{hrs}$ and GNT was $144 \pm 1.22 \mu \mathrm{g} / \mathrm{cm}^{2} \mathrm{hrs}$. It indicated that the EGCG penetration rate from GT was faster than non-transfersomal one. Another important parameter is lag time, the time for an active substance takes to permeate through the membrane and diffuse into the receptor fluid and then finally reach a steady state of diffusion. In this study, lag time of GT was $1.66 \pm 0.38 \mathrm{hrs}$, while GNT was $12.35 \pm 0.30 \mathrm{hrs}$. It showed that lag time of GT was quicker than GNT [37].

Penetration of EGCG from GT is higher than the GNT because GT contains phospholipid and surfactant so that the active substance penetrates easily to the lipid bilayer membrane of the skin. On the other hand, GNT just contains green tea extract. Transfersomes are a form of elastic or a deformable vesicle [38]. Penetration of the transfersome is 5 times smaller than the diameter of the transfersome itself. Transfersomes are composed of phospholipids like phosphatidylcholine which selfassembles into lipid bilayer, in an aqueous environment and closes to form a vesicle. Transfersomes in the formula had an edge activator function which can create deformability of transfersomes by decreasing the surface tension, therefore, transfersomes could penetrate through the smaller pores $[6,25,39]$. The transfersomes penetration mechanism

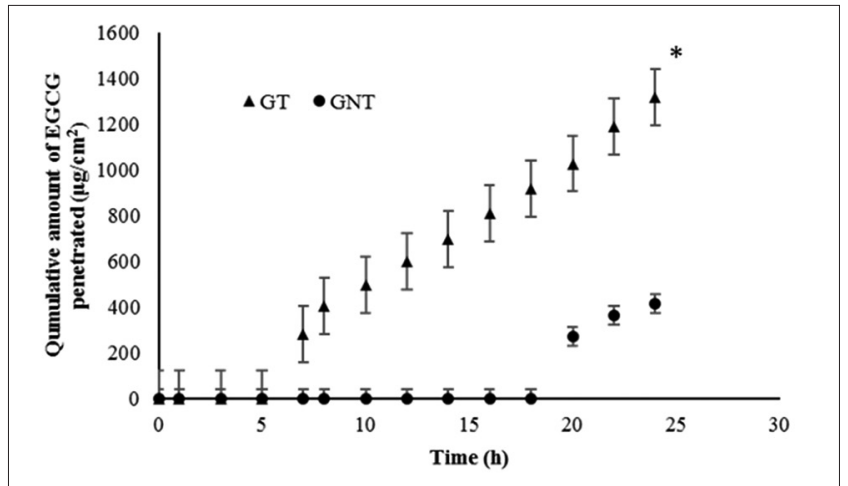

Fig. 2: Graph of cumulative of epigallocatechin gallate in transfersomal gel (GT) and non-transfersomal gel (GNT): GT and GNT. All values were represented as mean \pm standard deviation $(n=3) .{ }^{*} p<0.05$ compared to control formula (GNT)

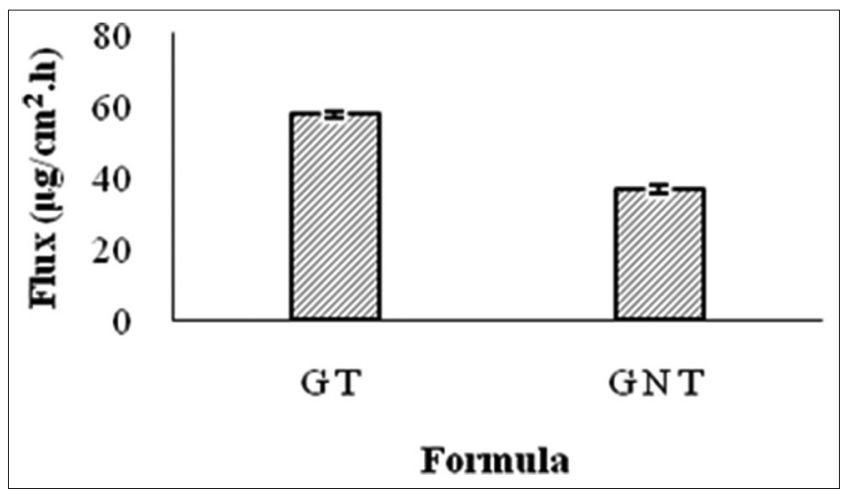

Fig. 3: Average penetration flux epigallocatechin gallate from gels: Transfersomal gel and non-transfersomal gel. All values were represented as mean \pm standard deviation $(n=3)$

into the skin follows the osmotic gradient mechanism that evaporates water when the transfersomes are applied on the skin surface [38]. The osmotic gradient is formed by the skin's ability as a penetrating barrier, preventing loss of moisture from the skin and maintaining a water content difference of $75 \%$ in the epidermis and almost dry or about $15 \%$ on the skin surface. The polar part of the lipid bilayer arrangement of the skin may draw water on the skin surface and the lipid bilayer generally spontaneously withstands dehydration of the skin. Therefore, vesicles that have a lipid bilayer arrangement will move from areas that have low water content to areas with high water content. As a result, when vesicles are applied to the surface of the skin, the lipid vesicles will be attracted to the skin. As an elastic vesicle, vesicles can enter through the pores of the stratum corneum and deform if they are of a small enough size. As with liposomes, the vesicle system cannot deform form because it has a lower penetration ability than transfersomes [40].

The presence of propylene glycol in the gel formula also increased the penetration of EGCG. Setty et al. had observed that propylene glycol is a key factor that can affect the drug release [41]. Based on the physicochemical parameter, drugs' molecular weight which penetrates through the skin should $<400 \mathrm{Da}$, and the partition coefficient value which could penetrate was $-1-4$ [42]. The higher the molecular weight of the active substances, then the longer time needed for the active substance to penetrate. EGCG's molecular weight was $458.37 \mathrm{~g} / \mathrm{mol}$, and the partition coefficient was $0.48[15,43]$. It is proved that entrapping EGCG into transfersome can alter its penetration through the skin because the partition coefficient can affect drug penetration [15].

Another factor that can influence drug penetration is viscosity of vehicle. Pednekar et al. explained that the cumulative amount of drug 
penetrated will decrease by the increase of viscosity [44]. In this study, GT had a lower viscosity than GNT. These results had a linear correlation with the amount of EGCG penetrated, and this is in line with the theory above. Based on the results above, it revealed that ethosomal gel can be used as a transdermal dosage form, and this statement is in accordance to the results of Garg et al. [45]

\section{CONCLUSION}

In conclusion, this study showed that GT significantly increased the in vitro penetration of EGCG from green tea leaves extract through the skin of rats compared to non-transfersomal one. The GT formulation can provide better absorption characteristics and enhance the penetration of the active substances and improve the stability of the drugs.

\section{ACKNOWLEDGMENTS}

The authors are highly thankful to Universitas Indonesia who had given a financial support for this research, particularly for PITTA Research Grants 2016.

\section{REFERENCES}

1. Sachan R, Tarun P, Soniya S, Vishal S, Gaurav S, Satyanand T, et al. Drug carrier transfersomes: A novel tool for transdermal drug delivery system. Int J Res Dev Pharm Life Sci 2013;2(2):309-16.

2. Hirva S, Jenisha P. Bicelle: A lipid nanostructure for transdermal delivery. J Crit Rev 2016;3(2):17-22.

3. Gupta NK, Dixit VK. Development and evaluation of vesicular system for curcumin delivery. Arch Dermatol Res 2011;303(2):89-101.

4. Elnaggar YS, El-Refaie WM, El-Massik MA, Abdallah OY. Lecithinbased nanostructured gels for skin delivery: An update on state of art and recent applications. J Control Release 2014;180:10-24.

5. Scognamiglio I, De Stefano D, Campani V, Mayol L, Carnuccio R, Fabbrocini G, et al. Nanocarriers for topical administration of resveratrol: A comparative study. Int J Pharm 2013;440(2):179-87.

6. Benson HA. Transfersomes for transdermal drug delivery. Expert Opin Drug Deliv 2006;3(6):727-37.

7. Gupta A, Aggarwal G, Singla S, Arora R. Transfersomes: A novel vesicular carrier for enhanced transdermal delivery of sertraline: Development, characterization, and performance evaluation. Sci Pharm 2012;80(4):1061-80

8. Sarmah P, Bhupen K, Anil KS. Transfersomes based transdermal drug delivery: An overview. Int J Adv Pharm Res 2013;12:2555-63.

9. Leuva S, Trust P, Mahila P. Development and characterization of curcumin loaded transfersome for transdermal delivery. J Pharm Sci Res 2009;1(4):71-80.

10. Namita P, Mukesh R, Vijay KJ. Camellia sinensis (green tea): A review. Glob J Pharmacol 2012;6(2):52-9.

11. Sharangi AB. Medicinal and therapeutic potentialities of tea (Camellia sinensis L.) - A review. Food Res Int 2009;42(5-6):529-35.

12. Anand J, Upadhaya B, Rawat P, Rai N. Biochemical characterization and pharmacognosy evaluation of purified catechins in green tea (Camellia sinensis) cultivars in India. 3 Biotech 2015;5(3):285-94.

13. Legeay S, Rodier M, Fillon L, Faure S, Clere, N. Epigallocatechin gallate: A review of its beneficial properties to prevent metabolic syndrome. Nutrients 2015;7(7):5443-68.

14. Mereles D, Hunstein W. Epigallocatechin-3-gallate (EGCG) for clinical trials: More pitfalls than promises? Int J Mol Sci 2011;12:5592-603

15. Sharma A, Saini S, Rana AC. Transdermal drug delivery system: A review. Int J Res Pharm Biomed Sci 2013;4(1):286-92.

16. Bhalaria MK, Naik S, Misra AN. Ethosome: A novel delivery system for antifungal drugs in the treatment of topical fungal disease. Indian $\mathrm{J}$ Exp Biol 2009;47(5):368-75.

17. Avadhani KS, Manikkath J, Tiwari M, Chandrasekhar M, Godavarthi A, Vidya SM, et al. Skin delivery of epigallocatechin-3-gallate (EGCG) and hyaluronic acid loaded nano-transfersomes for antioxidant and anti-aging effects in UV radiation induced skin damage. Drug Deliv 2017;24(1):61-74

18. Laxmi MV, Zafaruddin Md, Kuchana V. Design and characterization of transfersomal gel of repaglinide. Int Res J Pharm 2015;6(1):37-41.
19. Kulkarni R, Yadav JD, Vaidya KA, Gandhi PP. Transferosomes: An emerging tool for effective transdermal drug delivery. Int J Pharm Sci Res 2011;2(4):735-41.

20. Duangjit S, Opanasopit P, Rojanarata T, Ngawhirunpat T. Evaluation of meloxicam-loaded cationic transfersomes as transdermal drug delivery carriers. AAPS PharmSciTech 2013;14(1):133-40.

21. Walve JR, Bakliwal SR, Rane BR, Pawar SP. Transfersomes: A surrogated carrier for transdermal drug delivery system. Int J Appl Biol Pharm Technol 2011;2:204-13.

22. Chaudhary H, Kohli K, Kumar V. Nano-transfersomes as a novel carrier for transdermal delivery. Int J Pharm 2013;454(1):367-80.

23. Doaa AH, Dalia AE, Sally A, Mohamed AE. Formulation and evaluation of fluconazole topical gel. Int J Pharm Pharm Sci 2012;4(5):176-83.

24. Nash RA. Pharmaceutical Dosage form, Disperse System. Vol. 2. New York: St. John's University Jamaica; 2009. p. 38-9, 206-17, 193-4.

25. Jacob L, Anop KR. A review on surfactants as edge activators in ultradeformable vesicles for enhanced skin delivery. Int J Pharm Bio Sci 2013;4(3):337-44.

26. Patel R, Singh SK, Singh S, Sheth NR, Gendle R. Development and characterization of curcumin loaded transfersome for transdermal delivery. J Pharm Sci Res 2009;1(4):71-80.

27. Ramadon D, Aisha GW, Anwar E. Novel transdermal ethosomal gel containing green tea (Camellia sinensis L. Kuntze) leaves extract: Formulation and in-vitro penetration study. J Y Pharm 2017;9(3):1-5.

28. Malvern I. Dynamic Light Scattering. New York: Plenum Press; 2011. p. 1-6.

29. Shiny A, Toomu MC, Dhurke RK. Enhanced dermal delivery of nadifloxacin using liposomes. Int J Appl Pharm 2016;8(4):53-9.

30. Bajaj S, Dinesh S, Neha S. Stability testing of pharmaceutical products. J Appl Pharm Sci 2012;2(3):129-38.

31. Batchelder RJ, Calder RJ, Thomas CP, Heard CM. In vitro transdermal delivery of the major catechins and caffeine from extract of Camellia sinensis. Int J Pharm 2004;283(1-2):45-51.

32. Bonacucina G, Martelli S, Palmieri GF. Rheological, mucoadhesive and release properties of carbopol gels in hydrophilic cosolvents. Int $\mathrm{J}$ Pharm 2004;282(1-2):115-30.

33. A-sasutjarit R, Sirivat A, Vayumhasuwan P. Viscoelastic properties of carbopol 940 gels and their relationships to piroxicam diffusion coefficients in gel bases. Pharm Res 2005;22(12):2134-40.

34. Tamburic S, Craig DQ. The effects of ageing on the rheological, dielectric and mucoadhesive properties of poly(acrylic acid) gel systems. Pharm Res 1996;13(2):279-83.

35. Kalyani V, Babu KM, Kishore M. Transfersomes: An emerging tool for effective transdermal drug delivery. J Chem Pharm Sci 2014;7:236-41.

36. Malakar J, Sen SO, Nayak AK, Sen KK. Formulation, optimization and evaluation of transferosomal gel for transdermal insulin delivery. Saudi Pharm J 2012;20(4):355-63.

37. Prajapati ST, Patel CG, Patel CN. Transfersomes: A vesicular carrier system for transdermal drug delivery. Asian J Biochem Pharm Res 2011;2(2):507-24

38. Shaji J, Maria LA. Novel double loaded transferosomes: Evidence of superior anti-inflammatory efficacy - A comparative study. Int J Cur Pharm Res 2014;6(2):16-25.

39. Girhepunjel K, Kinikar D, Pal R. Transfersomes: A novel carrier for enhancer dermal delivery drug. World J Pharm Res 2014;3(2):2003-9.

40. Setty CM, Babubhai SR, Pathan IB. Development of valdecoxib topical gels: Effect of formulation variables on the release of valdecoxib. Int $\mathrm{J}$ Pharm Pharm Sci 2010;2 Suppl 1:70-3.

41. Misal G, Dixit G, Gulkari V. Formulation and evaluation of herbal gel. Indian J Nat Prod Res 2012;3(4):501-5.

42. Chandrashekar NS, Shobha Rani RH. Physicochemical and pharmacokinetic parameters in drug selection and loading for transdermal drug delivery. Indian J Pharm Sci 2008;70(1):94-6.

43. Anwar E, Ramadon D, Harmita H. Formulation and evaluation of gel and emulgel of chili extract (Capsicum frutescens L.) As topical dosage forms. Int J Pharm Pharm Sci 2014;6 Suppl 3:13-6.

44. Pednekar A, Dandagi P, Gadad A, Mastiholimath V. Formulation and characterisation of meloxicam loaded emulgel for topical application. Int J Pharm Pharm Sci 2015;7(11):216-22.

45. Garg AK, Negi LM, Chauhan M. Gel containing ethosomal vesicles for transdermal delivery of aceclofenac. Int $\mathrm{J}$ Pharm Pharm Sci 2010;2 Suppl 2:102-8 